Western University

Scholarship@Western

$5-1-2020$

\title{
Standards of care for children in emergency departments: executive summary.
}

Rodrick K Lim

Department of Paediatrics \& Medicine, Schulich School of Medicine, London, ON, rlim@uwo.ca

Baljit Cheema

Catherine Cartman

Department of Paediatrics \& Medicine, Schulich School of Medicine, London, ON

Ffion Davies

Marianne Gausche-Hill

See next page for additional authors

Follow this and additional works at: https://ir.lib.uwo.ca/paedpub

Part of the Pediatrics Commons

\section{Citation of this paper:}

Lim, Rodrick K; Cheema, Baljit; Cartman, Catherine; Davies, Ffion; Gausche-Hill, Marianne; and Hay, Felix, "Standards of care for children in emergency departments: executive summary." (2020). Paediatrics Publications. 535.

https://ir.lib.uwo.ca/paedpub/535 
Authors

Rodrick K Lim, Baljit Cheema, Catherine Cartman, Ffion Davies, Marianne Gausche-Hill, and Felix Hay 


\section{Standards of care for children in emergency departments: executive summary}

Rodrick K. Lim, MD FRCPC*; Baljit Cheema, MB, BS, BSc, MRCPCH, DTM\&H, MPhil ${ }^{\dagger}$; Catherine Cartman, BA, LLB*; Ffion Davies, MBChB, FRCPCH, FRCEM ${ }^{\ddagger}$; Marianne Gausche-Hill, MD, FACEP, FAAP, FAEMS\$; Felix Hay, RNC, Bsc Hons, MMed Sciף

\section{EXECUTIVE SUMMARY}

Published peer-reviewed standards of care is recognized as critical to driving improvements in quality of children's emergency care. ${ }^{1,2}$ Although standards for the emergency care of children exist at national levels, particularly in high-income countries, ${ }^{3-6}$ these are rare in low- and middle-income countries but do exist in some places. $^{7}$ The Standards of Care for Children in Emergency Departments V3.0 produced by the Paediatric Emergency Medicine Special Interest Group (PEMSIG) for the International Federation for Emergency Medicine, is unique in that it delineates valuable practical standards applicable on a global level, for both highincome and low- and middle-income country settings.

The standards recognize the varying challenges inherent in different parts of the world, including differences in patient load, burden of disease, staffing, infrastructure, access to education in pediatric emergency care, equipment, and medications. It is essential to consider the special requirements of the pediatric patient with respect to the environment, equipment, staff skills and training and to have a lead person champion the cause of raising awareness of the special needs of children.

The first set of International Federation for Emergency Medicine (IFEM) standards for the emergency care of children was published in 2012, using an expert consensus approach, with an updated version (Standards 2.0) being published in 2014. In 2019, V3.0 was published consisting of a 25 -chapter document aiming to guide hospitals in defining minimal standards of care for children in established or evolving emergency departments (EDs).

Essential and desirable standards were developed by consensus with global experts to ensure that EDs are prepared to care for children with critical illness or injury, to promote patient safety and to provide a benchmark for professional development. The standards will be of assistance to doctors, nurses, and administrators alike.

This executive summary will provide a brief overview of the Standards of Care for Children in Emergency Departments V3.0. ${ }^{8}$ The standards are summarised under headings that represent chapters in the document. Further detail is available in the full document, which is available online in the Supplemental Appendix.

\section{INTEGRATED SERVICES}

The design of health services in a region has an impact on the care of sick children. Prehospital, primary care, and hospital services for emergency pediatric care should be integrated, and the role of, and capabilities of, each hospital in the network should be clearly communicated and coordinated with emergency medical services (EMS). All EDs should be prepared at all times to be able to resuscitate a child brought in unexpectedly. Clear, written guidelines for transferring a child to specialized pediatric centers must exist as well as a mechanism for the efficient transfer of the child. EDs should be

From the ${ }^{*}$ Department of Paediatrics \& Medicine, Schulich School of Medicine, London, ON; ${ }^{\dagger}$ Division of Emergency Medicine, University of Cape Town, Cape Town, South Africa; ${ }^{\ddagger}$ University Hospitals of Leicester, Leicester, England; ${ }^{5}$ Departments of Emergency Medicine and Pediatrics, David Geffen School of Medicine at UCLA Harbor-UCLA Medical Center, Los Angeles, California; and the "University Hospitals of Leicester, Leicester, England.

Correspondence to: Dr. Rodrick Lim, Children's Hospital at London Health Sciences Centre, 800 Commissioners Road East, London, ON N6C 2V5; Email: rod.lim@Ihsc.on.ca

(c) Canadian Association of Emergency Physicians 2020

CJEM 2020;22(3):280-284

DOI 10.1017/cem.2020.1 
adequately staffed and equipped to deal with the full range of ages and ailments of the patients it normally receives. There should be access to specialist advice 24 hours a day, whether in person or facilitated by the use of technology, such as the Internet, telephone, or telehealth.

\section{CHILD AND FAMILY-CENTERED CARE}

Child- and family-centered care is recognized as essential to meeting the needs of pediatric patients. This model of care must inform the physical design of the ED as well as staffing and clinical practice. The ED must be a safe place for children, and it must protect them from the distressing sights and sounds of other patients. It must accommodate the child's family and make allowances for nutrition including breast-feeding. ED staff must present their advice and explanations clearly and in a manner that the family can understand and carry out. All children seen in the ED must be discharged with a letter they can keep and/or a letter sent to their general practitioner or primary health care provider. Guidelines for medical treatment that balance the wishes of the child, the guardian, and the child's best interests should also be available.

\section{INITIAL ASSESSMENT OF ILL OR INJURED CHILDREN}

Fear often makes pediatric patients more difficult to assess than adults. The initial assessment of an ill or injured child, therefore, requires different triage models that must be applied flexibly according to the situation. Every child arriving in the ED must undergo a rapid visual inspection when they arrive. All staff members must be trained to alert others to the arrival of a seriously ill child. ED staff should be highly competent in recognizing the seriously ill child and the signs of a deteriorating condition. No barriers should impede the immediate initial assessment and a full assessment by trained staff should take place within 15 minutes of arrival. Unstable children should not be delayed in triage. Their vital signs can be measured in the resuscitation area and weight may be estimated using standard tools for very sick or unstable children. Patients in moderate or severe pain should be provided with pain relief within 30 minutes of arrival.

\section{STABILISING AND TREATING ILL OR INJURED CHILDREN}

At a minimum, to stabilize and treat a child, all ED staff must be highly competent in resuscitation and basic pediatric life support. A clearly defined resuscitation team should be established. Advanced airway management should be provided rapidly based on the identified need. Trained staff should remain with the child. Resuscitation algorithms and equipment should be readily available and regularly reviewed by ED staff. Basic radiology and laboratory services should be available at all times to support the ED. Pediatric specific equipment, supplies, and medications should be easily and efficiently accessible (such as through the use of trolleys or carts) 24 hours a day. The equipment and medications should have a standardized layout, and they should be reviewed and updated so as to maintain stringent quality control and compliance with international guidelines. In areas lacking access to recommended equipment and medications, informed and rational decisions about alternatives must be made.

\section{ED STAFFING}

Staffing requires adequate numbers of people to cover all areas of the ED where children are being cared for, at all times, and who have the skills necessary to treat pediatric patients. Acquiring a critical mass of trained staff with pediatric skills may require investment into hiring and training. To avoid decision-making and patient care errors, it is essential that staff not work more than 12 hours at a time and, due to the high incidence of burnout, ED staff mental health and welfare should be prioritized to retain staff. Staff should also have access to decision support tools to assist in correct dosing, equipment sizing, and clinical pathways for pediatric illness and injury. Work schedules can take into account the peaks and troughs of pediatric arrivals, but in academic institutions, clinical staff members must have enough protected time to engage in research, education, and training.

\section{STAFF TRAINING}

Training ED staff must include typical EM skills for children of all ages, such as triage, airway skills, resuscitation, teamwork, observation, medication delivery, and procedures. Given the low frequency of pediatric resuscitations, it is imperative that these skills be practiced regularly and that refresher training be made available in a timely way. Better team skills result in better pediatric outcomes; therefore, these skills should also be taught and practiced using simulation with mannequins as teams of colleagues from different backgrounds 
practicing together. Senior staff must be physically present and available to teach junior medical and nursing staff while they work. These senior teachers must not be expected to carry a full clinical load while they teach, to ensure proper supervision and education in the busy ED environment. A senior ED physician and nurse should be appointed to create interdisciplinary educational training opportunities.

\section{EQUIPMENT SUPPLIES AND MEDICATIONS}

One of the many challenges for treating patients of all ages in an ED is ensuring availability of equipment and medications in sizes and formulations suitable for different ages and body weights. The scope of pediatric emergency medicine (PEM) practice needs to cover patients from a premature neonate weighing a few hundred grams to adolescents of adult-size. EDs must be equipped with all the necessary equipment, supplies, and medications needed for the care of the acutely ill or injured child patients, on a 24-hour basis. These should be easily accessible, clearly labeled, and safely organised, maintained, and stocked, even during peak activity. Staff may be specially assigned for this task.

\section{QUALITY \& SAFETY}

Patient safety is "the avoidance, prevention and amelioration of adverse outcomes or injuries stemming from the process of healthcare" whereas quality of care is discussed in terms of effectiveness, efficiency, timeliness, safety, equality of access to care, and patient-centered care. Safety in a pediatric emergency care has additional challenges that can increase the likelihood of error such as variation in weight-based medication dosing, among other factors. Therefore, EDs must have a program of continuous quality improvement that regularly examines patient safety and quality of care. Children must be weighed in kilograms (with the exception of children requiring emergency stabilization as noted above), and their weight should be recorded with their vital signs. Medical notes must be reviewed regularly to identify gaps in knowledge that result in risk to patients. Continuing education of staff must close those gaps. The quality improvement plan of the ED must include pediatric patient and disease-specific indicators. Effective communication between staff and family is key.

\section{POLICIES PROCEDURES \& GUIDELINES}

Institutional policies defining the goals of the organization and procedures directing the specific steps to be taken must include the general assessment and management of pediatric patients in the ED such as staffing, patient flow, triage, pain and vital signs assessment, resuscitation, infectious diseases, transfers, etc. ED staff, including staff who do not regularly work in the $\mathrm{ED}$, must have access to and familiarity with these documents, and the documents should be updated according to local and international evidence-based practice. Staff should also be educated about and have access to clinical care guidelines describing how clinical care should be conducted for a particular ailment or condition.

\section{INFORMATION SYSTEMS \& DATA}

In order for an ED to run efficiently, directors must know how many patients are in the ED, how many are high priority, how long individual patients have been waiting, etc. In creating a data management system for an ED, special consideration must be given to the unique needs of the pediatric patient. The opportunity to build in special adaptations to meet the needs of pediatric patients, such as prescribing alerts to avert dosing errors, should be used. The data management system should be integrated within the overall ED data management system and be able to connect to health information outside the ED. A specific pediatric point person must be integrally involved with the creation of the system and the regular review of the system.

\section{PREHOSPITAL CARE}

Children are less likely to arrive at the ED by ambulance because they are easier to transport. Nevertheless, prehospital or EMS personnel should be trained at a minimum to safely assess, manage, and transport pediatric emergencies and be competent in first aid and basic life support for infants, children, and adolescents alike. The expected level of skill should be defined and must include skills to address the needs of the child and family, and to assess the scene and factors surrounding the call for the risk of child abuse. EMS vehicles must all carry equipment, supplies, and medication suitable for children of all ages. 


\section{MASS CASUALTY OR PATIENT SURGES}

When an ED experiences higher than normal arrivals as the result of a local incident, epidemic, or mass casualty, for example, normal priorities may need to be adjusted if the need exceeds the resources available. Children have a higher incidence of mortality in these situations and children under 5 years of age are particularly vulnerable. All hospital staff training must, therefore, include care of the pediatric patient during surges and major incidents, and it must consider children's increased vulnerability when making hazard vulnerability assessments and case scenarios. The designated sites within the hospital for decontamination and management of patients in the incident must also consider child casualties. There must be a preplanned process to identify and treat unaccompanied children. Food, formula, diapers, and other supplies to care for daily needs of infants, children, and adolescents should be stocked and available.

\section{SAFEGUARDING CHILDREN (FROM ABUSE)}

Article 19 of the United Nations Convention on the Rights of the Child provides the child's right to be protected from all forms of physical or mental violence, injury, abuse, or neglect. ED staff must be able to recognize and manage children presenting as the result of abuse or neglect, and they must be able to do this in a culturally sensitive and appropriate manner. Clinicians must be aware of local laws regarding consent to examine a child as well as the proper authorities to notify when cases are suspected. The first responsibility of ED staff in the case of suspected abuse is to attend to the child's needs, including treatment of injury and provision of analgesia. Data information systems should be designed to identify children attending the ED frequently as well as those with known safeguarding concerns whether caused by an adult or other children. The medical chart should carefully document the clinician's findings, including photographs, illustrations, and detailed descriptions. Patients should not be discharged until a safe home is identified. Ultimately, abuse and neglect are complex problems requiring a multifaceted and multidisciplinary approach.

\section{ADOLESCENT MENTAL HEALTH \& ADOLESCENT SUBSTANCE MISUSE}

Adolescent care must respect their autonomy while remembering that they are not yet fully mature. They are a group distinct from both young children and adults, and it is at this time that mental health problems can develop, as well as experimentation with drugs and alcohol. Patients who arrive with a mental health or substance misuse problem must receive timely care by experienced staff. As with the case of abuse and neglect, ED staff must be familiar with the legislation surrounding consent, confidentiality, and mental capacity of patients under the legal age of adulthood. Staff involved in using restraint must be specifically trained to do so for pediatric patients.

\section{DEATH OF A CHILD IN ED}

ED physicians must be familiar with local and state laws as well as the institutional policies of their hospital regarding the death of a child. Cardiopulmonary resuscitation (CPR) must be administered initially (until information is verified) unless there are unmistakable signs of death or there is a legally valid written directive not to initiate CPR or other forms of life saving treatment. Staff must be prepared for and helped with the emotional effects of dealing with a child's death.

\section{ADVANCED TRAINING AND ACADEMIC RESEARCH}

To further develop PEM as a distinct specialty, research is necessary. It is also required to improve pediatric patient care, teaching, and training. The ED should foster such activity, usually under the auspices of a university or in partnership with it.

\section{SUMMARY}

The Standards of Care for Children in Emergency Departments V3.0 has been developed by consensus of an international group of experts on behalf of IFEM. These standards are unique in that they provide international standards specifically aimed at ED settings globally. There are clearly huge differences in aspects such as staffing, equipment, and methods of handling child patients between various countries depending on where that nation is with respect to pediatric emergency care development. The priorities of improving the quality of emergency care for children in high-income countries with advanced EDs, will differ from low- and middle-income countries who 
have evolving emergency medical infrastructures. However, regardless of the resource level of the environment, improving quality of care will be an incremental process. Having practical and applicable standards will be of value to planning and advocacy efforts aimed at attaining higher quality emergency care for children in all settings.

Keywords: Administration, global health, pediatrics

Supplemental material: The supplemental material for this article can be found at https://doi.org/10.1017/cem.2020.1.

\section{Competing interests: None declared.}

Acknowledgements: Members of the PEMSIG Authorship Group: Dr. Angelina Ang, MD; Franz Babl, MD, MPH, DMedSc, FRACP, FAAP, FACEP; Heloise Buys; Liliana Caceres, MD, Simon Chu, MBBS, DCH, FACEM, MMed; Sashikumar Ganapathy, MB, BCh, BAO, MRCPCH(UK); Camilo E. Gutierrez, MD, FACEP, FAAEM; Zaw Lwin, MBBS, MRCPCH(UK), FRCP(Edin); Brianna McKelvie, MD, Msc; Prinetha Moodley, MBChB(Natal), FCPaeds(SA); Ed Oakley, MBBS; Andrew Rowland, BMedSci(Hons), BMBS(Hons), MFMLM, MAcadMEd, FRCEM, FRCPCH, FRSA Honorary Professor (Paediatrics); Indumathy Santhanam, MD, DCH; Teng Sung Shin, MBBS, MRCPCH(UK); Javeed Sukhera, MD, PhD; Rahim Valani, CCFP(EM), FRCP, MBA, M Med Ed; Patrick Van de Voorde, MD, PhD; Yehezkel (Hezi) Waisman; Adriana Yock-Corrales, MD, MSc.

\section{REFERENCE}

1. Molyneux EM, Webber MW. Applying the right standards to improve hospital performance in Africa. Lancet 2004;364:1560-1.

2. Cheema B. International standards of care for children in emergency mcentres - do they apply to Africa? Afr 7 Emerg Med 2013;3:50-1

3. RCPCH. Facing the Future - Standards for Children and Young People in Emergency Care Settings. 2018. Available at: https://www.rcpch.ac.uk/resources/facing-future-standardschildren-young-people-emergency-care-settings (accessed January 20, 2020).

4. Remick K, Gausche-Hill M, Joseph M, Brown K, Snow S, Wright J. Pediatric readiness in the emergency department. Pediatrics 2018;142(5)pii e21082459.

5. Remick K, Gausche-Hill M, Joseph M, Brown K, Snow S, Wright J. Pediatric readiness in the emergency department. Ann Emerg Med 2018;72(6):e123-e136.

6. Remick K, Gausche-Hill M, Joseph M, Brown K, Snow S, Wright J. Pediatric readiness in the emergency department. 7 Emerg Nurs 2019;45(1):e3-e18.

7. Cheema B, Westwood A (eds.) Standards for Paediatric Emergency Care: Expert Consensus Report for the Western Cape [Internet]. 2015 [cited November 24, 2015]. Available at: http://www.emct.info/standards-for-paediatric-emergency-care. html (accessed January 20, 2020).

8. International Federation for Emergency Medicine. Standards of Care for Children in Emergency Departments. Version 3.0; 2019. Available at: https://www.ifem.cc/wp-content/uploads/ 2019/06/Standards-of-Care-for-Children-in-EmergencyDepartments-V3-2019.pdf (accessed October 21, 2019). 